\title{
Role of Ascorbic Acid Versus Silymarin in Amelioration of Hepatotoxicity Induced by Acrylamide in Adult Male Albino Rats: Histological and Immunohistochemical Study
}

\author{
Rol del Ácido Ascórbico Frente a la Silimarina en la Mejoría de la Hepatotoxicidad Inducida \\ por Acrilamida en Ratas Albinas Macho Adultas: Estudio Histológico e Inmunohistoquímico
}

\author{
Ahmed Salman ${ }^{1,2}$; Dalia El-Sayed El-Ghazouly ${ }^{3} \&$ Maha El Beltagy ${ }^{1,2}$
}

SALMAN, AH; EL-GHAZOULY, DALIA EL-SAYED 3 \& EL BELTAGY, M. Role of ascorbic acid versus silymarin in amelioration of hepatotoxicity induced by acrylamide in adult male albino rats: histological and immunohistochemical study. Int. J. Morphol., 38(6):1767-1778, 2020 .

SUMMARY: Acrylamide (ACR) is a cytotoxic and carcinogenic material. It is a product of a Maillard reaction during the cooking of many types of fried fast food, e.g. potato chip fries, and chicken nuggets. ACR has a severe toxic effect on different body organs. This study investigates the hepatotoxic effect of ACR, and the protective effect of ascorbic acid and silymarin. For this purpose, forty adult, male, albino rats were divided into four groups and received the following treatments for fourteen days: Group I: (the control) normal saline; Group II: ACR only; Group III: ACR and ascorbic acid; and Group IV: ACR and silymarin. Under a light microscope, the liver from rats treated with ACR only presented disturbed liver architecture, degenerated hepatocytes, reduced glycogen contents, congested central vein, and increased collagen fibres with areas of fibrosis. Immunohistochemical examination revealed an increased mean number of CD68-, and $\alpha$-SMA-positive cells. This indicates the presence of large numbers of stellate macrophages (Kupffer cells) and Hepatic stellate cells (HSCs). The combination of ACR with either ascorbic acid or silymarin resulted in less hepatic degeneration, less fibrosis and fewer CD68 and $\alpha$-SMA positive cells compared to the ACR only group. In conclusion, treatment with silymarin or ascorbic acid along with ACR appears to alleviate ACR-induced hepatotoxicity with more protection in silymarin treated rats.

KEY WORDS: Liver; Ascorbic acid; Silymarin; Acrylamide; CD68; $\alpha$-SMA.

\section{INTRODUCTION}

Acrylamide (ACR) is a highly reactive, water-soluble, unsaturated, amide monomer, used in many industries; for example, cosmetics, paper, textile, wastewater treatment and printing (Rosen \& Hellenas, 2002).

The high temperature $\left(>120^{\circ} \mathrm{C}\right)$ cooking of foods induces a Maillard reaction between monosaccharides, and amino acids, such as fructose or glucose, and asparagine, respectively.

This reaction leads to ACR formation, so people may be exposed to ACR toxicity through ingestion of carbohydraterich food, cooked above $120^{\circ} \mathrm{C}$ (Tareke et al., 2002).

ACR is highly concentrated in used frying oil and cigarette smoke. Many foods contain high levels of ACR, such as cereals, chocolate, potato chip fries, crackers and bread (Tareke et al.).
The World Health Organisation (WHO), and the United Nations Food and Agriculture Organisation (FAO) reported that food containing ACR might be a severe hazard to human health (Rosen \& Hellenas).

Many researches have proven that ACR intake affected the health of animals. It has a toxic effect on the nervous system (Lehning et al., 2003), body genes (Manière et al., 2005) and also has a carcinogenic effect (Hogervorst et al., 2010). The ACR absorbed in the digestive system is transported to the liver, where it is metabolised (Shipp et al., 2006). Other studies detected that ACR has a toxic effect on the rat liver (Yousef \& El-Demerdash, 2006).

Ascorbic acid is one of the dominant antioxidants, sustaining the intracellular antioxidant system. Moreover, it has an anti-inflammatory function through eradication of reactive oxygen species, which stimulate pro-inflammatory

\footnotetext{
${ }^{1}$ Department of Anatomy, Faculty of Medicine, Menoufia University, Egypt.

${ }^{2}$ Department of Anatomy and Histology, Faculty of Medicine, The University of Jordan, Amman, Jordan.

${ }^{3}$ Department of Histology, Faculty of Medicine, Menoufia University, Egypt.
} 
cytokines in diverse inflammatory illness and liver fibrosis (Reuter et al., 2010). Therefore, ascorbic acid and vitamin $\mathrm{E}$ supplementation improve liver function, and prevent fibrosis in patients with non-alcoholic steatohepatitis (Harrison et al., 2003). Furthermore, ascorbic acid alone reduces hepatic injury in an experimental model of acute ischemia in rats (Huseyin et al., 2017).

Silymarin is a flavonoid compound extracted from a medical plant called Silybum marianum. It inhibits lipid peroxidation and related cell destruction. It is considered an antioxidant, anti-fibrotic, anti-neoplastic and hepato-protective agent (Soto et al., 1998).

Its hepato-protective effect is manifested in preventing toxic materials from passing into hepatocytes, activating liver rejuvenation through its antioxidant effect (Soto et al.) and downregulating the activity of inflammatory mediators (Wu et al., 2008).

Moreover, it is considered an anti-cirrhotic agent, as it prevents stellate hepatocytes from being converted into myofibroblasts; thus, inhibiting collagen fibre deposition(Kara et al., 2008).

The aim of the study. This study aims to evaluate the ameliorative roles of ascorbic acid and silymarin on ACRinduced hepatotoxicity in adult male albino rats.

\section{MATERIAL AND METHOD}

Chemicals. Acrylamide, as powder, $99 \%$ purity (catalogue No: A9099, Sigma-Aldrich, St. Louis, MO, USA), Ascorbic Acid (AS) (catalogue No: A92902, Sigma-Aldrich, St. Louis, MO, USA), and Silymarin (catalogue No: S0292, Sigma-Aldrich, St. Louis, MO, USA).

Animals. Forty adult male albino rats weighing $200( \pm 20)$ grams were used in this study, following approval of the protocol by the Medical Research Ethics Committee, Faculty of Medicine, Menoufia University. They were housed under standard conditions of temperature $\left(23 \pm 2{ }^{\circ} \mathrm{C}\right)$ and lighting $(12 \mathrm{~h} \mathrm{light/}$ dark cycles), with free access to food and drinking water. All rats received care in accordance with the rules and regulations of the Medical Research Ethics Committee, Faculty of Medicine, Menoufia University.

Methods. Rats were randomly divided into four groups ( $\mathrm{n}=10$ per group).

Group I: Control group: Rats received normal saline (0.9\%) intraperitoneally (IP) throughout the experiment.
Group II: ACR group: Rats were treated with ACR (50 mg per $\mathrm{kg}$ per day IP) for 14 days (Motamed-Shariaty et al., 2014).

Group III: ACR + Ascorbic acid group: Rats were treated with both ascorbic acid (150 mg/kg of body weight per day orally) (Mumtaz et al., 2019) and ACR (50 mg per kg of body weight per day IP) for 14 days; the time interval between treatments is $1 \mathrm{~h}$.

Group IV: ACR + Silymarin group: Rats were treated with both silymarin (100 mg / kg of body weight per day orally) (Shaker et al., 2011), and ACR (50 mg per kg of body weight per day IP) for 14 days; the time interval between treatments is $1 \mathrm{~h}$.

At the end of the experiment, the rats were sacrificed, and the liver removed. The specimen was fixed in $10 \%$ formaldehyde for 48 hours. After processing to make paraffin blocks, $7 \mathrm{~mm}$ sections were cut and stained with Haematoxylin \& Eosin (H\&E) stain for routine histological examination, Masson trichrome stain for detection of hepatic collagen fibres, and PAS to detect hepatocyte glycogen content.

Immunohistochemical staining. Immunohistochemical staining with CD68 and $\alpha$-Smooth muscle actin ( $\alpha$-SMA) was performed on formalin-fixed paraffin sections. CD68 is a lysosomal glycoprotein used for detection of stellate macrophages (Kupffer cells) (Lefkowitch et al., 2002); CD68, Ab-3, a mouse monoclonal antibody, (Clone KP1; Lab Vision Corp., Neo Markers Inc./ Lab Vision, Fremont, California, USA). $\alpha$-SMA (clone 1A4, a mouse monoclonal antibody; Sigma Chemical Co., St Louis, Missouri, USA) was used as an indicator of Hepatic stellate cell (HSC) activation (Tamaki et $a l ., 2008)$. For immuno-detection, paraffin sections ( $5 \mu \mathrm{m})$ were mounted on poly-L-lysine coated slides. After de-paraffinisation in xylene, and rehydration in descending grades of ethanol, the slides were rinsed in $0.02 \%$ PBS. Then the primary antibody was added for $1 \mathrm{~h}$ at room temperature; some slides were incubated with CD68 antibody at a dilution 1:100 in PBS and others were incubated with anti- $\alpha$-SMA at a dilution of 1:100 in PBS. After washing in PBS, the sections were incubated in goat anti-mouse immunoglobulin (the secondary antibody) for $30 \mathrm{~min}$ at room temperature. Streptavidin peroxidase was applied for $10 \mathrm{~min}$ at room temperature and the sections were rinsed in PBS. The slides were incubated in a solution of 0.05 $\%$ diaminobenzidine (Sigma Chemical Co.) for 5-15 min and then washed in distilled water. All the sections were counterstained with Mayer's haematoxylin, dehydrated and mounted (Carbone et al., 1993).

\section{Quantitative morphometric measurements}

1.The area percentage of collagen fibres. The percentage of area containing collagen fibres was measured in Masson's trichrome-stained sections at a magnification of $\times 100$. 
SALMAN, AH; EL-GHAZOULY, DALIA EL-SAYED 3 \& EL BELTAGY, M. Role of ascorbic acid versus silymarin in amelioration of hepatotoxicity induced by acrylamide in adult male albino rats: histological and immunohistochemical study. Int. J. Morphol., 38(6):1767-1778, 2020.

2.The number of CD68-positive cells. CD68-positive stellate macrophages (Kupffer cells) were counted in CD68 immuno-stained sections at a magnification of $\times 200$.

3.The number of $\alpha$-SMA-positive hepatic stellate cells (HSCs). $\alpha$-SMA-positive HSCs were counted in $\alpha$-SMA immunostained sections at a magnification of $\times 200$.

All measurements were taken using a computerised image analyser system (Leica Q 500 MC Program; Leica, Cambridge, UK), and were performed in 10 randomly chosen sections from five animals for each group.

Statistical analysis. All data were analysed statistically using GraphPad Prism version 4. Data were expressed as mean \pm SD and analysed using one-way analysis of variance (ANOVA) followed by Bonferroni's multiple comparison post-hoc tests for comparison between all groups. Differences were regarded as non-significant if $\mathrm{P}$ values were $>0.05$, and significant if $\mathrm{P}$ values were $\mathrm{p}<0.05$.

\section{RESULTS}

\section{Histological study}

Haematoxylin \& Eosin (H\&E) staining. Examination of H\&E-stained sections of the liver collected from the control group I revealed the normal histological architecture of the liver. The control liver was formed of classical hepatic lobules; each lobule was formed of a central vein with cords
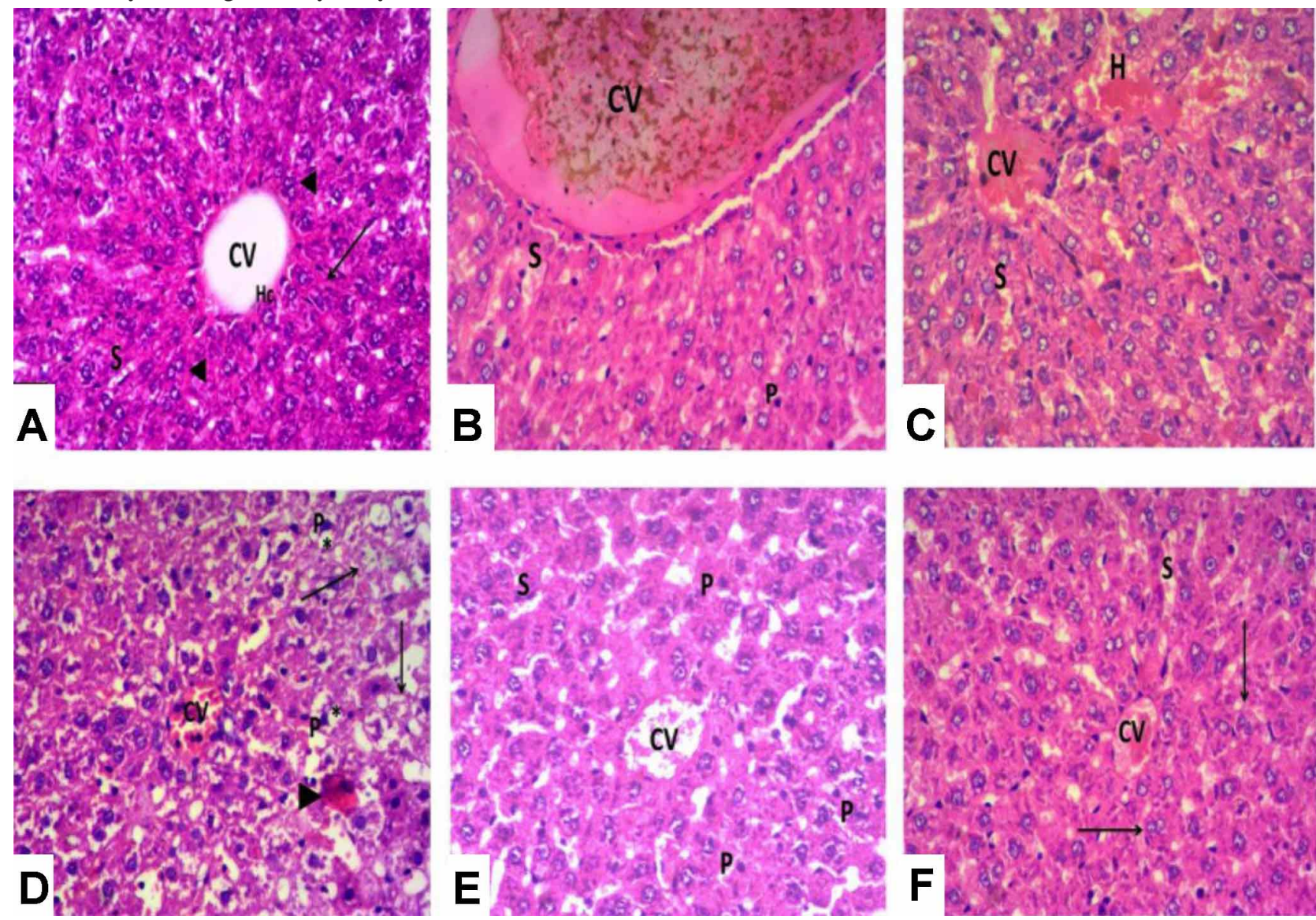

Fig. 1. Photomicrograph of H\&E-stained liver sections of the different groups: (a) Control group showing central vein (CV) with cords of hepatocytes $(\boldsymbol{\Lambda})$ radiating from it toward the periphery and separated by blood sinusoids $(\mathrm{S})$. Hepatocytes (Hc) have acidophilic cytoplasm and central rounded vesicular nuclei, some are binucleated $(\Delta)$. (b) ACR group showing marked dilatation and congestion of central vein $(\mathrm{CV})$, congested sinusoids (S), pyknotic nuclei (P) in some hepatocytes. (c) ACR group showing congested central vein $(\mathrm{CV})$, dilated congested sinusoids $(\mathrm{S})$, and haemorrhage $(\mathrm{H})$ in some areas. (d) ACR group showing congested central vein $(\mathrm{CV})$ with loss of hepatic architecture. Some hepatocytes show ballooning, vacuolated cytoplasm (*), pyknotic nuclei (P). Other hepatocytes appear vacuolated without nucleus $(\mathbf{\Delta})$. Note one hepatocyte with strong acidophilic cytoplasm and peripheral crescent-shaped nucleus $(\Delta)$. (e) ACR+Ascorbic acid group showing moderate congestion of central vein (CV) and blood sinusoids (S). Some hepatocytes appear with pyknotic nuclei (P). (f) ACR+Silymarin group showing mild congestion in central vein (CV) and sinusoids (S). Hepatocytes appear normal, regularly arranged with acidophilic cytoplasm and vesicular nuclei. Note binucleated cells $(\mathbf{\Delta})$. H \& E, $\times 200$. 
SALMAN, AH; EL-GHAZOULY, DALIA EL-SAYED 3 \& EL BELTAGY, M. Role of ascorbic acid versus silymarin in amelioration of hepatotoxicity induced by acrylamide in adult male albino rats: histological and immunohistochemical study. Int. J. Morphol., 38(6):1767-1778, 2020.

of hepatocytes radiating from the central vein towards the periphery of the lobule (Fig. 1a). The portal tracts appeared normal and contained branches of the hepatic artery, portal vein, and bile duct (Fig. 2a). Sections from the ACR-treated group II revealed many histopathological changes, such as loss of hepatic architecture with degenerated hepatocytes. Some had vacuolated cytoplasm and deeply stained pyknotic shrunken nuclei. There was marked dilatation and congestion of the central vein and blood sinusoids, with haemorrhage in some areas (Fig. 1 b-d). The portal areas revealed massive peri-portal cellular infiltration, dilated congested portal vein and hepatic artery branches and proliferation of bile duct (Fig. 2 b-d). However, sections from group III, treated with ACR and ascorbic acid, and group IV, treated with ACR and silymarin, revealed less degenerative changes, compared to the ACR-treated group II. In particular, group IV appeared almost normal, except for some congestion in the central vein and blood sinusoids (Fig.s. 1 e, f, and 2 e, f).

Masson's trichrome staining. Masson's trichrome-stained sections of the control group I revealed minimal collagen fibres around the central veins, and in the portal tract area. (Fig. 3 a, b). The stained sections of the ACR-treated group II revealed extensive collagen fibre deposition around the central veins, in the portal tract areas, and in the perisinusoidal spaces (Fig. 3 c, d). Sections from groups III and IV showed a noticeable reduction in collagen fibre deposition compared with the ACR-treated group II, especially in group IV, which showed presented as nearly similar to the control (Fig. 3 e-h).
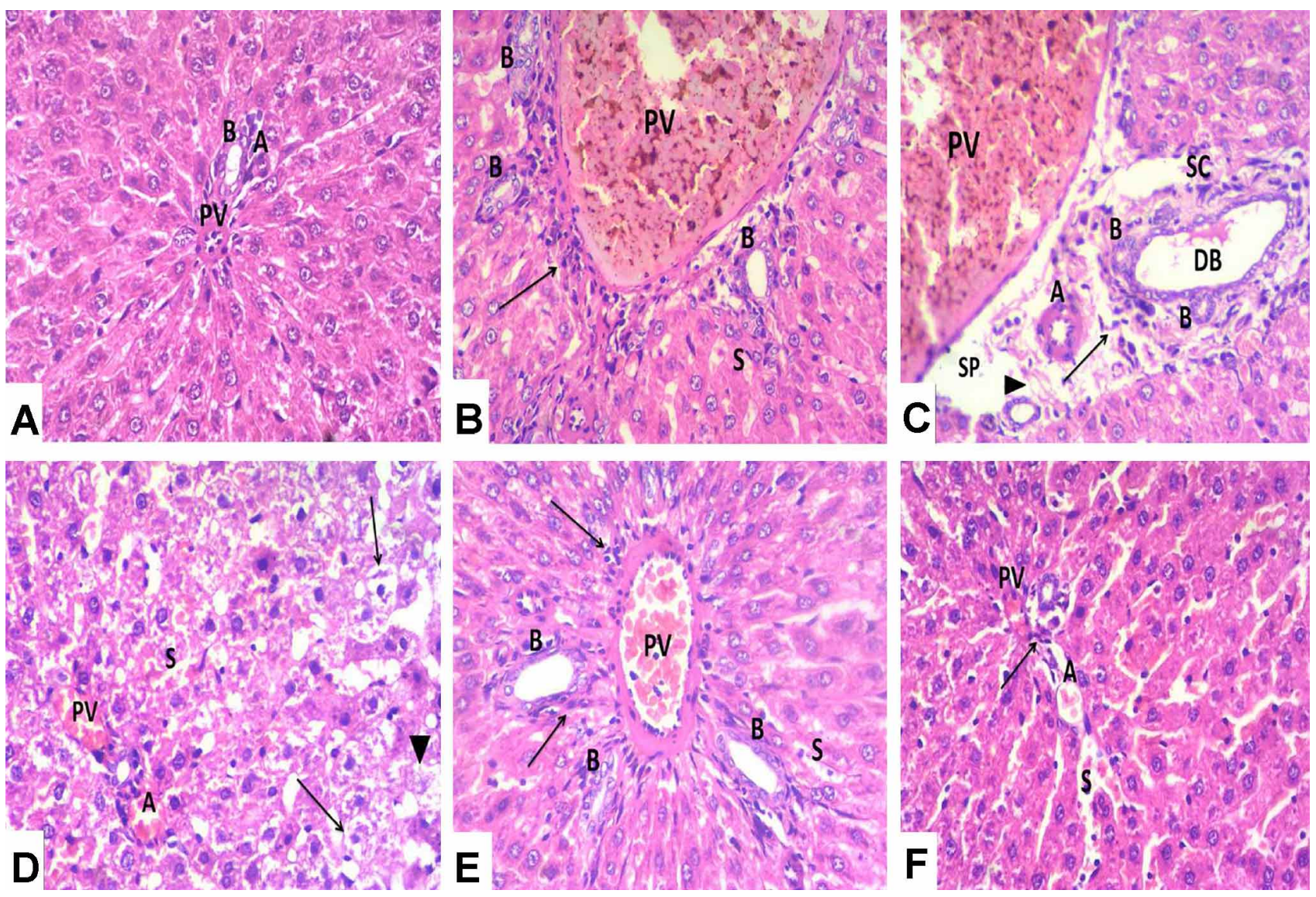

Fig. 2. Photomicrograph of H\&E-stained liver sections of the different groups: (a) Control group showing portal tract containing portal vein (PV), hepatic artery (A), bile duct (B). (b) ACR group showing marked dilatation and congestion of portal vein (PV) with massive periportal cellular infiltration $(\mathbf{\Delta})$. Note proliferation of bile duct (B), congested sinusoids (S). (c) ACR group showing congested dilated portal vein $(\mathrm{PV})$. Elongated and dilated bile duct (DB) with retained secretion is observed. Note proliferation of bile duct (B), wide spacing (Sp) in portal area with some eosinophilic fibrous matrial $(\Delta)$. Stellate cell (SC), Some inflammatory cells $(\boldsymbol{\Delta})$, Hepatic artery $(A)$ are observed. (d) ACR group showing multiple ballooned hepatocytes $(\mathbf{\Lambda})$ having pyknotic nuclei and vacuolated cytoplasm, other cells appear without nucleus $(\Delta)$. Note congested portal vein (PV) and hepatic artery (A), congested sinusoids (S). (e) ACR+Ascorbic acid group showing some congestion in portal vein (PV) and sinusoids (S). Note proliferation of bile duct (B). Moderate periportal cellular infiltration ( $\mathbf{\Delta}$ ) is observed. (f) ACR+Silymarin group showing some congestion in portal vein (PV), hepatic artery (A) and sinusoids (S). Most hepatocytes appear regularly arranged with acidophilic cytoplasm and vesicular nuclei. Very minimal cellular infiltration ( $\mathbf{\Lambda})$ is observed. H \& E. $\times 200$. 

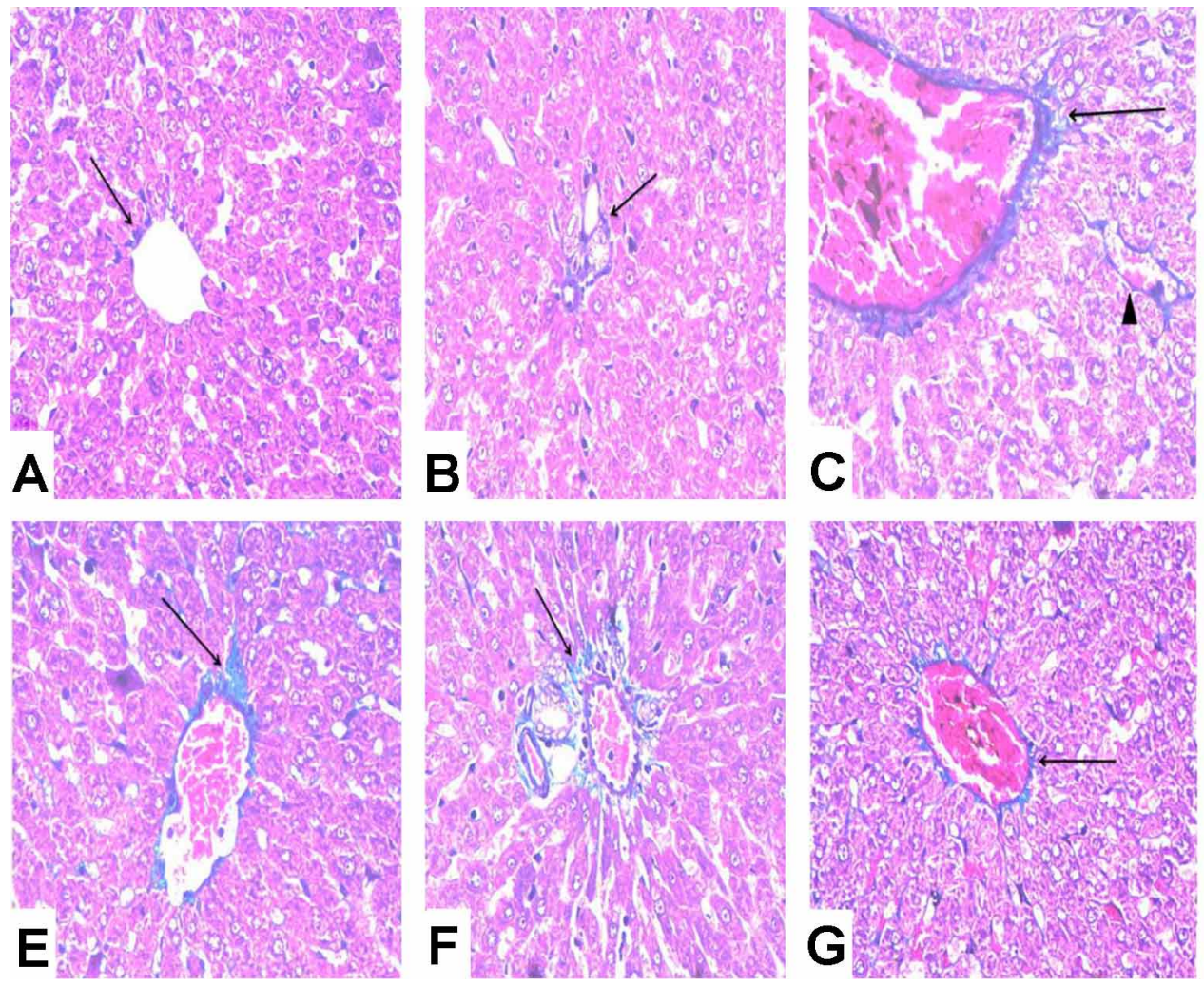
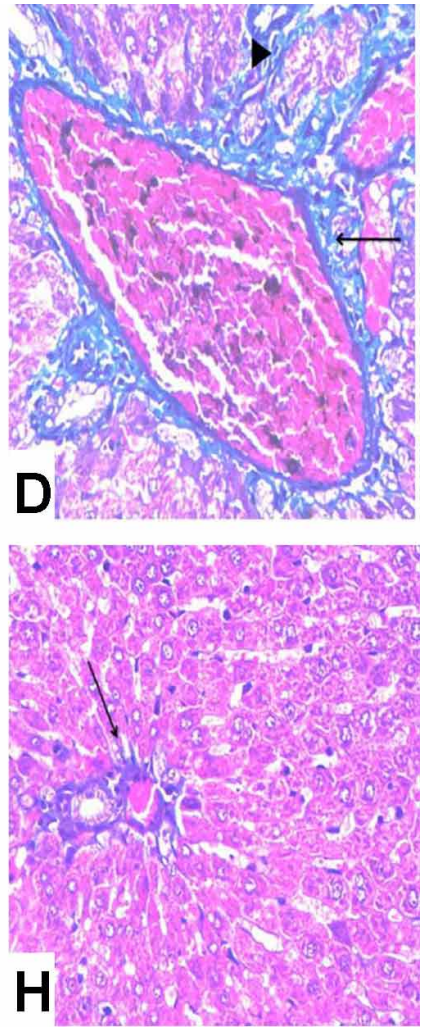

Fig. 3. Photomicrograph of Masson's Trichrome-stained liver sections of the different groups: (a) Control group showing minimal collagen fibres ( $\uparrow$ ) around the central vein. (b) Control group showing minimal amount of collagen fibres ( $\uparrow$ ) in the portal tract area. (c) ACR group showing extensive collagen fibre accumulation around a dilated central vein $(\uparrow)$ and extending in the perisinusoidal spaces $(\Delta)$. (d) ACR group showing extensive collagen fibre accumulation $(\uparrow)$ in the portal tract area and extending between hepatocytes $(\Delta)$. (e) ACR+Ascorbic acid group showing moderate amount of collagen fibres ( $\uparrow$ ) around the central vein. (f) ACR+Ascorbic acid group showing moderate amount of collagen fibres $(\uparrow)$ in the portal tract area. (g) ACR+Silymarin group showing few collagen fibres $(\uparrow)$ around the central vein. (h) ACR+Silymarin group showing few collagen fibres $(\uparrow)$ in the portal tract area. Masson's trichrome, $\times 200$.

Periodic Acid Schiff reaction (PAS). PAS-stained sections of the liver from the control group I revealed PAS-positive glycogen granules in the cytoplasm of hepatocytes, reflecting normal rich glycogen content of the hepatocytes (Fig. 4a). The ACR-treated group II revealed weak PAS reaction in some hepatocytes, and absence of the reaction from other cells, reflecting a reduction in the glycogen content of the hepatocytes (Fig. 4b). The stained sections of group III treated with both ACR and ascorbic acid demonstrated heterogeneous staining intensity of PAS reaction (Fig. 4c). Sections of group IV treated with both ACR and silymarin showed a strong PAS reaction (Fig. 4d).

\section{Immunohistochemical study}

Immunohistochemical staining for CD68. The CD68immunostained sections of control group I revealed mild CD68 positive immunoreactivity in stellate macrophages (Kuppfer cells) lining the blood sinusoids (Fig. 5a). CD68- immunostained sections of the ACR-treated group II revealed many enlarged stellate macrophages (Kupffer cells) with strong positive cytoplasmic CD68 immunoreactivity protruding or hanging in the lumen of a blood sinusoid (Fig. 5 b, c). The CD68-stained sections of groups III and IV showed mild CD68 immunoreactivity, and apparent reduction in the number of stellate macrophages with decreased staining intensity, when compared with the ACR-treated group II (Fig. 5 d, e).

\section{Immunohistochemical staining for $\alpha$-Smooth muscle} actin ( $\alpha$-SMA). The control group showed $\alpha$-SMA immunoreaction in the media of the portal area vessels. (Fig. 6 a). The ACR-treated group (II) revealed many aSMA immunoreactive HSCs between the hepatocytes, and in the media of the portal area vessels (Fig. 6 b, c). Group III and group IV showed some $\alpha$-SMA immunoreactive HSCs between the hepatocytes and in the media of the vessels of the portal area (Fig. $6 \mathrm{~d}$,e). 

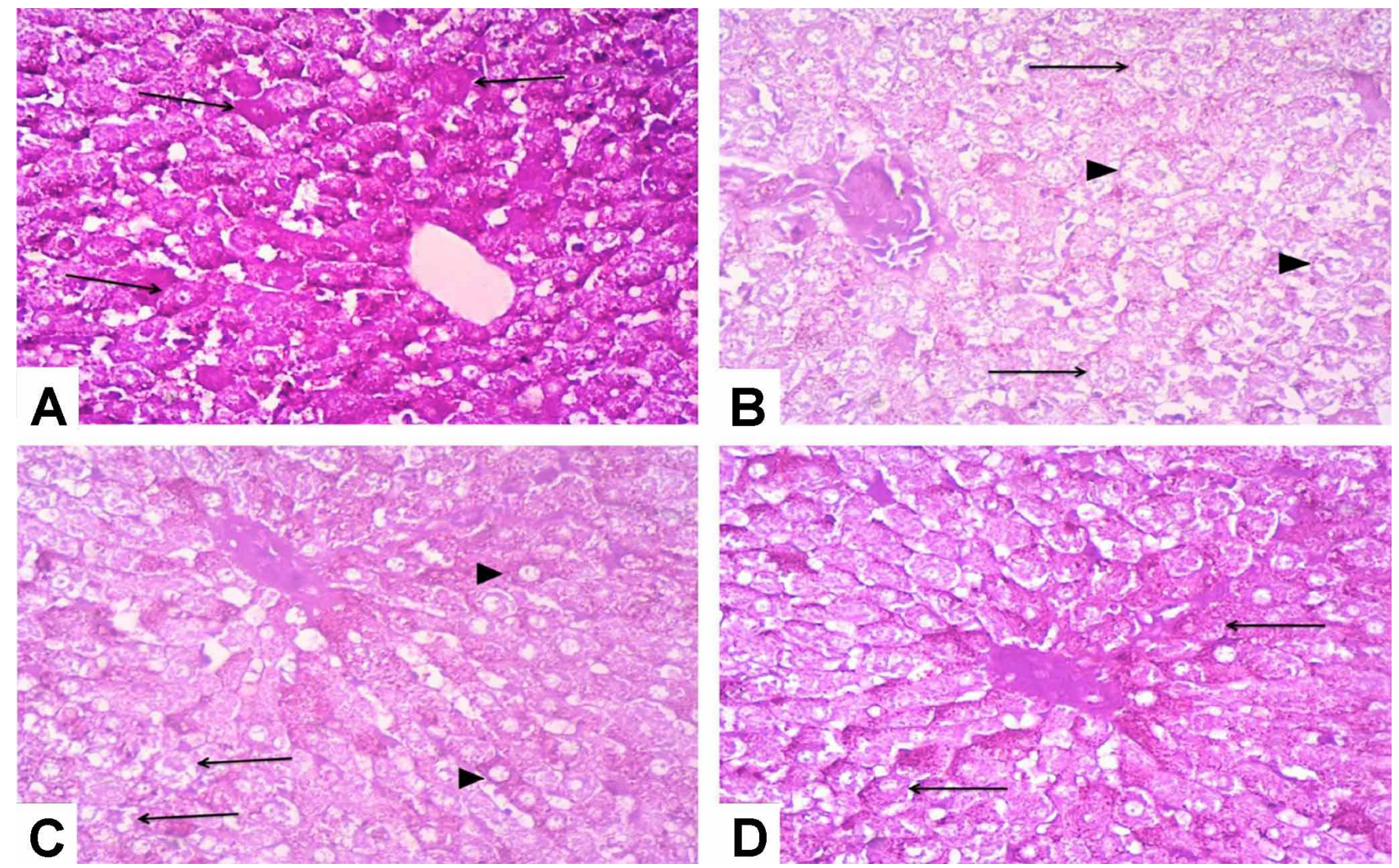

Fig. 4. Photomicrograph of Periodic Acid Schiff reaction (PAS)-stained liver sections of the different groups: (a) Control group showing positive deeply stained magenta red glycogen granules $(\mathbf{\Delta})$ in the cytoplasm of hepatocytes (very strong PAS reaction). (b) ACR group showing a weak PAS reaction $(\boldsymbol{\Delta})$ in the cytoplasm of hepatocytes. Other hepatocytes show no reaction $(\Delta)$. (c) ACR+Ascorbic acid group showing heterogeneous intensity of PAS reaction. Some hepatocytes show a strong PAS reaction $(\Delta)$, whereas other hepatocytes exhibit a weak PAS reaction ( $\mathbf{\Delta})$. (d) ACR+Silymarin group showing strong PAS reaction ( $\mathbf{\Delta})$ in the cytoplasm of hepatocytes. PAS $\times 200$

\section{Morphometric and statistical results}

1- The mean area percentage of collagen fibres. The ACRtreated group showed a highly significant increase in the mean area percentage of collagen fibres as compared to control group. In contrast, groups III and IV showed a highly significant decrease in the area percentage of collagen fibres compared with the ACR-treated group II (Table I; Fig. 7 a).

2- The mean number of CD68 positive cells. The treatment with ACR only in group II caused a highly significant increase in the mean number of CD68-positive Kuppfer cells compared with the control group I. Group III and IV showed a highly significant decrease in the mean number compared with the ACR-treated group II. Group IV showed a nonsignificant increase compared with the control group (Table I; Fig. 7b).

3- The mean number of $\alpha$-SMA-positive HSCs. The ACRtreated group showed a highly significant increase in the mean number of $\alpha$-SMA-positive HSCs compared to the control group. Groups III and IV showed a highly significant decrease in the mean number compared with the ACR-treated group II. However, they showed a non-significant increase compared with the control group I (Table I; Fig. 7 c).

\section{DISCUSSION}

ACR is a compound used in many industries; however, it has a severe toxic effect on the liver, kidney and brain (Elhelaly et al., 2019).

The Maillard reaction is a chemical reaction between an amino acid and a reducing sugar under the effect of heat. This produces ACR, giving the food its characteristic flavour. ACR is founded in food cooked, barbecued or fried above $120^{\circ} \mathrm{C}$ (Martinez et al., 2019).

This study showed that ACR induces hepatotoxicity in adult rats. This is evidenced by disturbed liver architecture, 

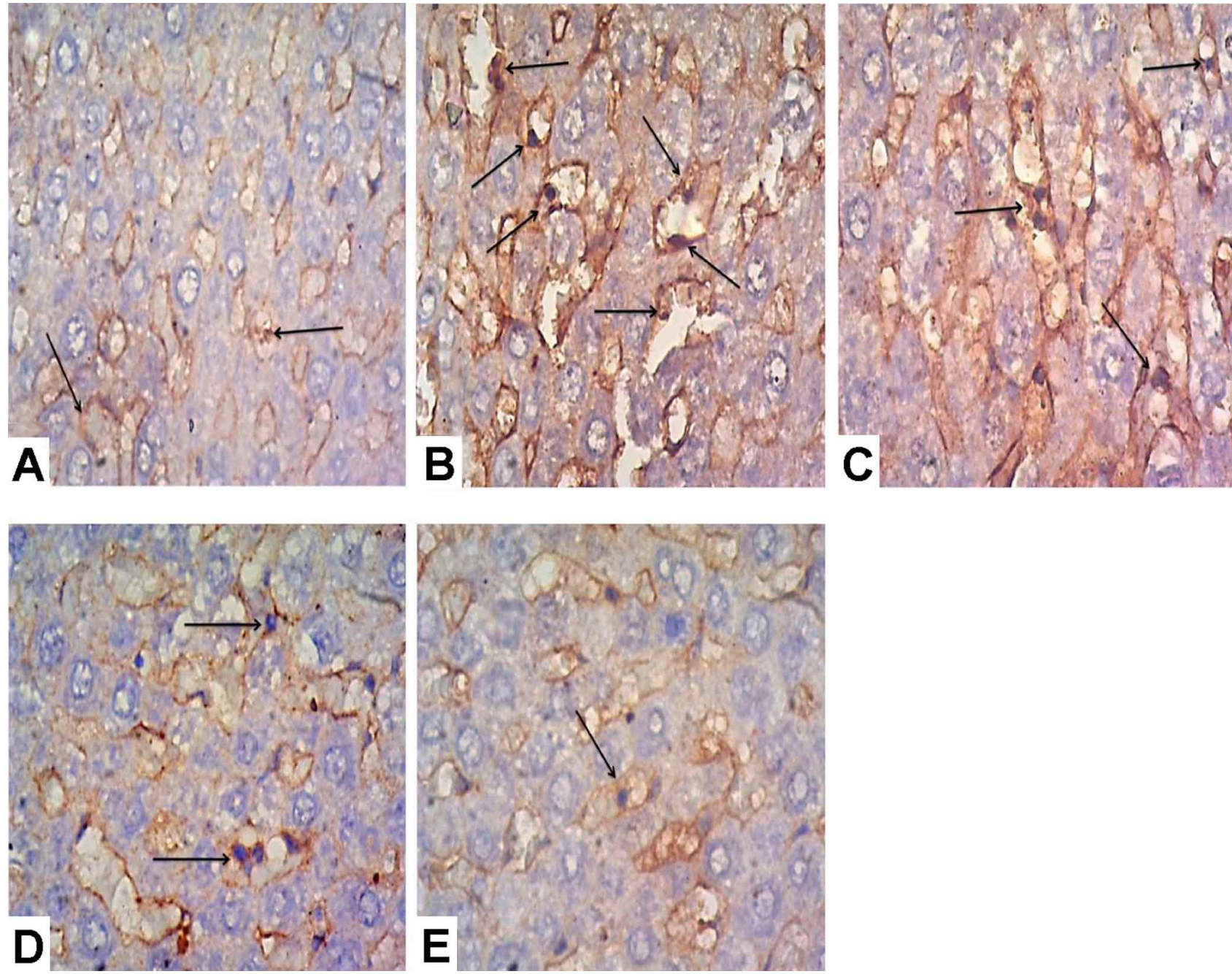

Fig. 5. Photomicrograph of CD68-stained liver sections of the different groups: (a) Control group showing mild CD68 positive immunoreactivity in Kuppfer cells ( $\mathbf{\Delta}$ ) lining the blood sinusoids. (b) ACR group showing strong CD68 positive immunoreactivity in many Kuppfer cells ( $\mathbf{\Delta})$ which appeared enlarged and protruding in the lumen of the blood sinusoids. (c) ACR group showing many enlarged in stellate macrophages (Kupffer cells) ( $\mathbf{\Delta}$ ) hanging in the lumen of a blood sinusoid with strong positive cytoplasmic CD68 immunoreactivity. (d) ACR+Ascorbic acid group showing some enlarged Macrophagocytus stellatus ( $\mathbf{\Delta}$ ) hanging in the lumen of blood sinusoids with moderate positive cytoplasmic CD68 immunoreactivity. (e) ACR+Silymarin group showing few stellate macrophages (Kupffer cells) $(\mathbf{\Lambda})$ hanging in the lumen of a blood sinusoid with mild positive cytoplasmic CD68 immunoreactivity. CD68 immunostaining, $\times 400$

vacuolated cytoplasm and pyknotic shrunken nuclei, depletion of glycogen content in hepatocytes and increased collagen fibre areas, in hepatocytes.

The antioxidant system controls free radicals formation. However, it may not eliminate the deleterious outcomes of the free radicals in all occasions, which cause oxidative devastation (Makhlouf et al., 2011).

Many studies have reported that ACR administration raises the production of free oxygen radicals and reduces the level of glutathione and glutathione-S-transferase activity.
Hence, it disturbs the oxidant/antioxidant balance and causes oxidative damage to the tissue. Furthermore, ACR overcomes the antioxidant system, thus causing oxidative stress (Veenapani et al., 2010).

Oxidative stress is triggered by oxidant/antioxidant imbalance, leading to oxidation of many biological molecules, causing destruction of cell organelles, disturbance of cell metabolism, DNA destruction and cell death. This mechanism is responsible for the pathogenesis of many diseases; e.g. diabetes, tumour formation, and hepatic diseases (Gren, 2013). Furthermore, oxidative stress plays a 

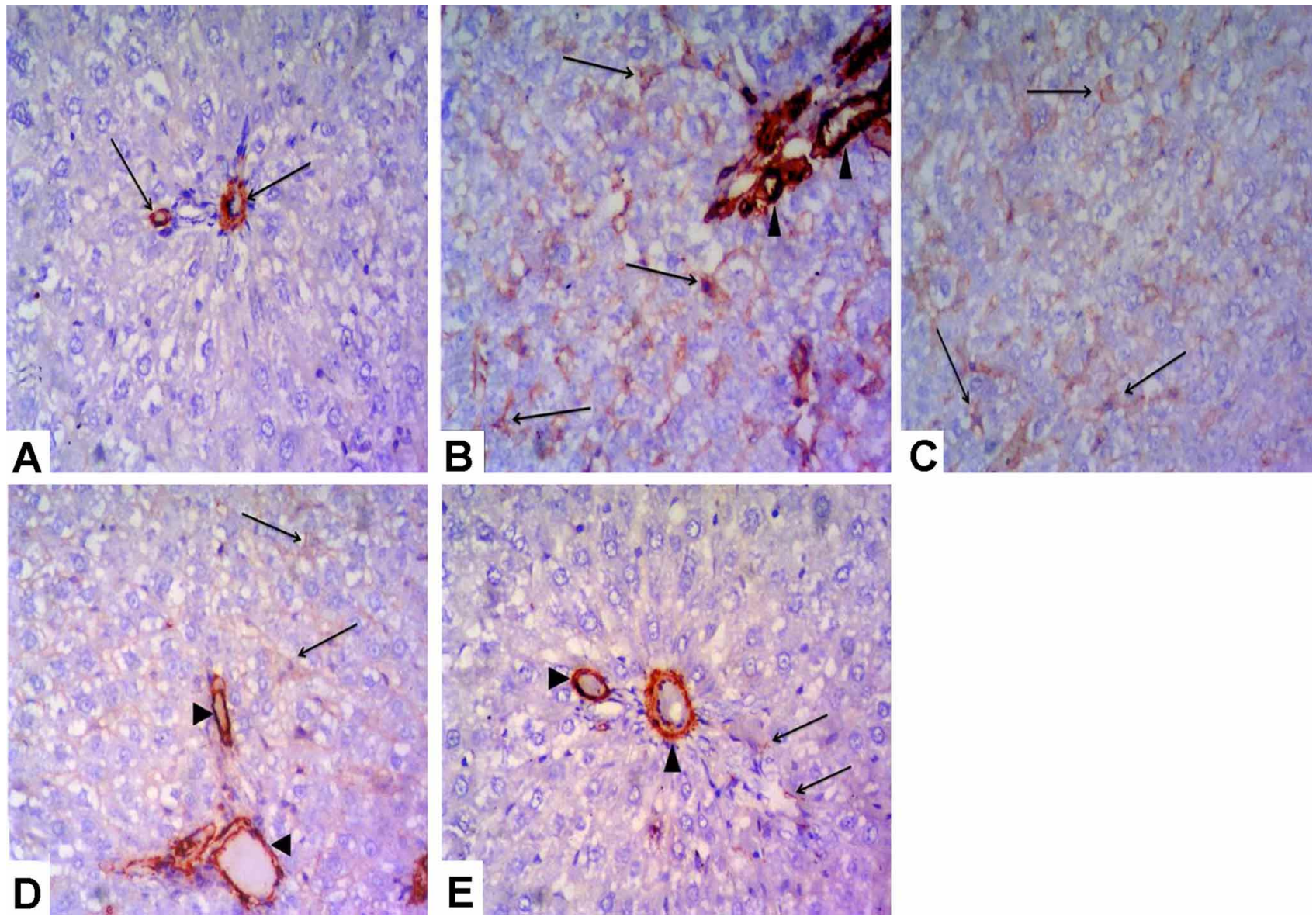

Fig. 6. Photomicrograph of $\alpha$-smooth muscle actin ( $\alpha$-SMA)-stained liver sections of the different groups: (a) Control group showing $\alpha$ SMA immunoreaction in the media of the vessels of the portal area ( $\mathbf{\Lambda})$. No positive immunoreactive cells were detected between the hepatocytes. (b) ACR group showing many $\alpha$-SMA immunoreactive cells (HSCs) that are stellate shaped with fine processes extending between the hepatocytes $(\mathbf{\Delta})$. The media of the blood vessels in the portal tract are also $\alpha$-SMA immunoreactive $(\Delta)$ ). (c) ACR group showing many $\alpha$-SMA immunoreactive HSCs that are stellate shaped with fine processes extending between the hepatocytes ( $\mathbf{\Delta}$ ). (d) ACR+Ascorbic acid group showing some $\alpha$-SMA immunoreactive HSCs between the hepatocytes ( $\mathbf{\Delta})$. The media of the blood vessels in the portal tract are also $\alpha$-SMA immunoreactive $(\Delta)$. (e) ACR+Silymarin group showing very few $\alpha$-SMA immunoreactive HSCs between the hepatocytes $(\boldsymbol{\Delta})$. The media of the blood vessels in the portal tract are also a-SMA immunoreactive $(\Delta)$. $\alpha$-SMA immunostaining, $\times 200$

Table I. The area percentage of collagen fibres, the number of CD68 positive cells and the number of $\alpha$-SMA positive HSCs in the control and experimental groups are expressed as mean \pm standard deviation (SD)

\begin{tabular}{lcccc}
\hline & Group I & Group II & Group III & Group IV \\
\hline $\begin{array}{l}\text { Percentage of area of } \\
\text { collagen fibres Mean } \pm \text { SD }\end{array}$ & $2.1 \pm 0.58$ & $18.7 \pm 1.47$ & $7.1 \pm 0.86$ & $3.8 \pm 0.81$ \\
$\begin{array}{l}\text { Number of CD 68 positive } \\
\text { cells Mean } \pm \text { SD }\end{array}$ & $6.5 \pm 1.049$ & $18.67 \pm 1.21$ & $11.5 \pm 1.049$ & $7.83 \pm 1.17$ \\
$\begin{array}{l}\text { Number of_SMA positive } \\
\text { HSCs Mean } \pm \text { SD }\end{array}$ & $0.00 \pm 0.00$ & $56.33 \pm 10.65$ & $19.17 \pm 3.66$ & $3.33 \pm 1.03$ \\
\hline
\end{tabular}

crucial role in hepatic fibrosis and increasing collagen fibres in the liver parenchyma of ACR intraperitoneal-injected rats (Alturfan et al., 2012).

Thiobarbituric acid is used to measure lipid peroxidation and superoxide dismutase, which is considered one of the major antioxidant enzymes. Levels were found to be elevated in the plasma, kidney and liver of rats treated with ACR (Yousef \& El-Demerdash). In addition, malondialdehyde is a lipid peroxidation marker, whose concentration was elevated in the brain of rats exposed to ACR (Semla et al., 2017). The above findings suggest the 


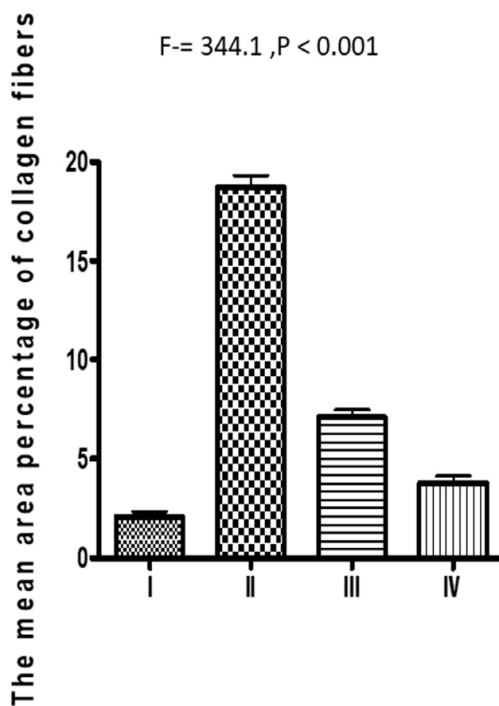

(a) Pairwise significant differences $(\mathrm{P}<0.001)$ were detected between: Group I and group II ; Group II and group III and IV.

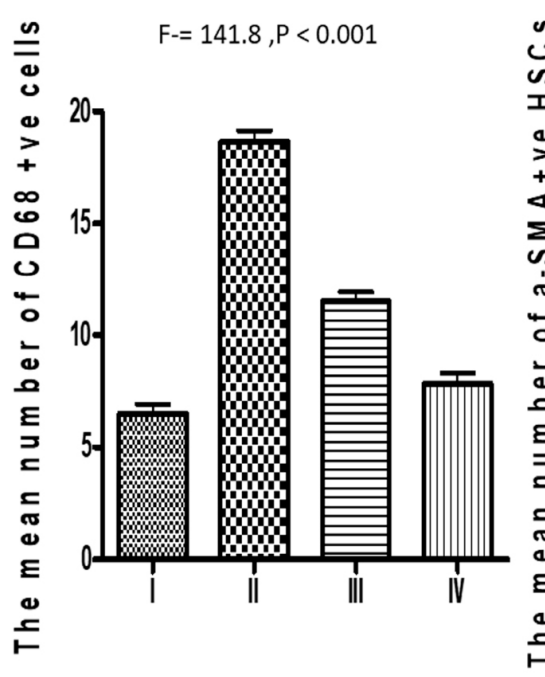

(b) Pairwise significant differences $(\mathrm{P}<0.001)$ were detected between: Group I and group II ; Group II and group III and IV.

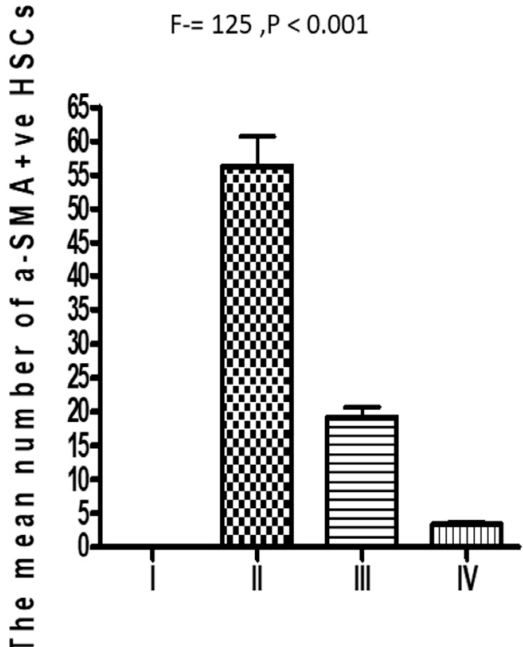

(c) Pairwise significant differences $(\mathrm{P}<0.001)$ were detected between: Group I and group II ; Group II and group III and IV.

\section{Group I : control. Group II : Acrylamide treated, Group III: Acrylamide and ascorbic acid Group IV Acrylamide and silymarin treated .}

Fig. 7. Graph showing comparison of (a) Percentage of area of collagen fibres,(b) Number of CD68 positive cells, (c) Number of $\alpha$-SMA positive HSCs in different groups.

role of ACR in augmentation of lipids peroxidation and redox imbalance.

The hepatocytes of the ACR-treated group had weak or no PAS reaction indicating declined glycogen content. This may be due to breakdown of glycogen molecules into glucose, as stated by Rawi et al. (2012).

On a study of the effect of ACR on female rats, Yue et al. (2020) reported depletion of hepatic glycogen and increased glycogen phosphorylase; the latter promotes glycogenolysis leading to decreased glycogen storage in the liver.

Moreover, one of cellular mechanism to compete with ACR toxicity is mobilizing glutathione, and augmentation of glutathione-S-transferase activity which leads to glycogen reduction in hepatocytes (Veenapani et al.).

The proliferation of bile duct was observed in H\&Estained sections of the ACR-treated group. Overi et al. (2018) state that the cells lining the bile ducts are kinds of stem cells that are activated, and proliferate, with necrosis or lysis of liver cells.
Under the condition of severe and chronic liver injury caused by drugs, viruses, and toxins, these stem cells were stimulated to proliferate and differentiate both into mature hepatocytes and biliary epithelial cells (Alison et al., 2001).

CD68 is a glycosylated glycoprotein, which is strongly expressed in macrophages. It is an immunostaining marker for macrophages in various inflammatory diseases (Ferenbach \& Hughes, 2008).

Stellate macrophages are considered one of the cells that express CD68. In a normal liver, Stellate macrophages have been considered as scavenger cells responsible for removing particulate matter from the portal circulation (Racanelli \& Rehermann, 2006). Actually, Stellate macrophages were considered as the first responder to any toxic substance reaching the liver, where they produce harmful mediators leading to subsequent hepatocyte injury (Kolios et al., 2007). In case of hepatocyte injury, Stellate macrophages proliferate, enlarge, and initiate inflammatory response by releasing multiple cytokines and growth factors (Suh \& Jeong, 2011).

$\alpha$-SMA was considered as a marker for the activated 
SALMAN, AH; EL-GHAZOULY, DALIA EL-SAYED 3 \& EL BELTAGY, M. Role of ascorbic acid versus silymarin in amelioration of hepatotoxicity induced by acrylamide in adult male albino rats: histological and immunohistochemical study. Int. J. Morphol., 38(6):1767-1778, 2020.

HSCs (Cheung et al., 2006). Under normal conditions, quiescent HSCs store retinol lipid droplets and produce small amounts of extracellular matrix (ECM) (Wu \& Zern, 2000).

Upon activation, HSCs lose their lipid content, undergo morphological transition to myofibroblast-like cells, and synthesise large amounts of ECM components, especially collagen I; thus inducing liver fibrosis (Cubero \& Nieto, 2006).

There was a cross-link between the hepatic fibrosis, increased number of Stellate macrophages and activated HSCs observed in the ACR-treated group in the current study. It was reported that hepatocyte injury led to the activation of Stellate macrophages that produced cytokines and growth factors (transforming growth factor-b). These factors activated HSCs, which proliferated and transformed into myofibroblasts-like cells that deposited large amounts of ECM. Moreover, activated Stellate macrophages decreased the expression of proteolytic enzymes, which broke down the ECM, thus initiating a fibrogenic response (Abdel-Hafez \& Othman, 2013).

Ascorbic acid is an organic compound and watersoluble vitamin crucial for many of the body's biological functions. It has antioxidant capability, and is considered an anti-inflammatory and immuno-stimulant (Angela et al., 2014)

Ascorbic acid decreased the concentration of inflammatory chemokine, which attenuated chemotaxis of granulocytes and neutrophils. Through this mechanism, ascorbic acid inhibits necroinflammatory activity. For that, the concentration of inflammatory chemokine and cytokineinduced neutrophil chemoattractant- 1 is elevated in rats with ascorbic acid deficiency

(Horio et al., 2006).

Ascorbic acid protected against acetaminophen hepatotoxicity by inhibition of oxidative stress (Kurahashi et al., 2016), and markedly decreased the hepatocyte cell death and liver fibrosis caused by bile acid (Yu et al., 2015).

In their study on the effect of hepatic toxicity of ACR, Ghorbel et al. (2015) reported that the level of ascorbic acid and glutathione decreased markedly.

Moreover, it has been reported that ascorbic acid decreased hepatic fibrosis by suppression of oxidative stress. It reduced protein peroxidation, protein oxidation and lipid products. Antioxidant enzymes, such as glutathione peroxidase, superoxide dismutase, and catalase were upregulated by ascorbic acid administration in rats with liver fibrosis due to alcoholic intake (Prathibha et al., 2013).

Many researchers studied the hepato-protective effect of silymarin in many liver diseases, like viral hepatitis, alcoholic and non-alcoholic liver disease, liver cirrhosis and hepatocellular carcinoma (Das et al., 2011).

Silymarin protected the rat liver against ethanol toxicity through reduction of oxidative stress, prevention of glutathione decline and rise of lipid peroxidation and Tumour necrosis factor alpha (TNF- $\alpha$ ) (Song et al., 2006). It also had a detoxifying effect, and protected the liver against toxic drugs, such as arsenic, acetaminophen and carbon tetrachloride (Das et al.).

Moreover, silymarin was found to decrease hepatocyte injury, oxidative stress factors, and fibrosis score, and also abolished activation of stellate macrophages and HSCs in a rat model of carbon tetrachloride toxicity (Clichici et al., 2014).

Silymarin has an anti-fibrotic effect. It suppresses fibrogenic gene expression and activation of HSCs in the liver of diabetic rats fed with a choline-deficient and methionine diet. The mechanism of this anti-fibrotic impact is attributed to antioxidant effect and elevation in nuclear translocation of Nuclear factor erythroid 2-related factor 2 (Nrf-2) (Kim et al., 2012).

Furthermore, silymarin reduced serum Interleukin-13, which plays an important role in hepatic fibrosis in mice infected with schistosomiasis mansoni (Chiaramonte et al., 2001).

Platelet-activating factor (PAF) plays an essential role in hepatic injury and development of fibrosis and cirrhosis. It was found that PAF, with existence of tissue inflammation, permitted HSCs to produce a major amount of collagen fibres. Silibin—one of silymarin's active ingredients—decreases PAF in cirrhotic rats, and also blocked its pro-fibrotic effect by the acetylation process, which was enhanced by elevation of Lysophosphatidylcholine acyltransferase enzymes (LPCAT) (Stanca et al., 2013).

An in vitro study on the protective effect of silymarin on ACR-treated PC12 cells revealed more cell viability, decreased reactive oxygen species and malondialdehyde, and elevation of glutathione levels; therefore, extenuating neurotoxicity produced by ACR in PC12 cells (Li et al., 2017).

In conclusion, this study demonstrated the ACR hepatotoxic effect. Treatment with oral ascorbic acid and silymarin appears to alleviate this induced hepatotoxicity with more protection in silymarin treated rats. 
SALMAN, AH; EL-GHAZOULY, DALIA EL-SAYED 3 \& EL BELTAGY, M. Papel del ácido ascórbico frente a la silimarina en la mejora de la hepatotoxicidad inducida por acrilamida en ratas albinas macho adultas: estudio histológico e inmunohistoquímico. Int. J. Morphol., 38(6):1767-1778, 2020.

RESUMEN: La acrilamida (ACR) es un material citotóxico y cancerígeno. Es producto de la reacción de Maillard durante la cocción de muchos tipos de comida rápida y frita, por ejemplo: papas fritas y nuggets de pollo. ACR tiene un efecto tóxico severo en diferentes órganos del cuerpo. Este estudio investigó el efecto hepatotóxico del ACR y el efecto protector del ácido ascórbico y la silimarina. Con este fin, cuarenta ratas albinas machos adultas se dividieron en cuatro grupos y recibieron los siguientes tratamientos durante catorce días: Grupo I (control), solución salina normal; Grupo II, solo ACR; Grupo III, ACR y ácido ascórbico; y Grupo IV, ACR y silimarina. Bajo microscopio óptico, el hígado de ratas tratadas con ACR solo presentó alteración de su arquitectura, entre ellos hepatocitos degenerados, contenido reducido de glucógeno, vena central congestionada y aumento de fibras de colágeno con áreas de fibrosis. El examen inmunohistoquímico reveló un aumento del número medio de células CD68 y $\alpha$-SMA positivas. Esto indica la presencia de un gran número de macrófagos estrellados (células de Kupffer) y células estrelladas hepáticas (HSC). La combinación de ACR con ácido ascórbico o silimarina resultó en menos degeneración hepática, menos fibrosis y menos células positivas para CD68 y $\alpha$-SMA en comparación con el grupo de ACR solo. En conclusión, el tratamiento con silimarina o ácido ascórbico junto con ACR parece aliviar la hepatotoxicidad inducida por ACR.

PALABRAS CLAVE: Hígado; Ácido ascórbico; Silimarina; Acrilamida; CD68; $\alpha$-SMA

\section{REFERENCES}

Abdel-Hafez, A. \& Othman, M. Effect of sildenafil citrate on the structure of rat liver. Egypt. J. Histol., 36:991-1003, 2013.

Alison, R.; Poulsom, R. \& Forbes, S. Update on hepatic stem cells. Liver, 21(6):367-73, 2001.

Alturfan, A.; Tozan-Beceren, A.; Sehirli, O.; Demiralp, E.; Sener, G. \& Omurtag, Z. Resveratrol ameliorates oxidative DNA damage and protects against acrylamide-induced oxidative stress in rats. Mol. Biol. Rep., 39(4):4589-96, 2012.

Angela, S.; Eliana, G.; Francesca, C.; Giovanni, C.; Giuseppe, C. \& Susan, C. Ascorbic acid: its role in immune system and chronic inflammation diseases. Mini Rev. Med. Chem., 14(5):444-52, 2014.

Carbone, A.; Gloghini, A.; Volpe, R. \& Pinto, A. KP1 (CD68)-positive large cell lymphomas: A histopathologic and immunophenotypic characterization of 12 cases. Hum. Pathol., 24(8):886-96, 1993.

Cheung, P.; Zhang, Q.; Zhang, Y.; Bai, G.; Lin, M., Chan, B. \& Yang, M. Effect of WeiJia on carbon tetrachloride induced chronic liver injury. World J. Gastroenterol., 12(12):1912-7, 2006.

Chiaramonte, M.; Cheever, A.; Malley, J.; Donaldson, D. \& Wynn, T. Studies of murine schistosomiasis reveal interleukin-13 blockade as a treatment for established and progressive liver fibrosis. Hepatology, 34(2):273-82, 2001.

Clichici, S.; Olteanu, D.; Nagy, A.; Oros, A.; Filip, A. \& Mircea, P.
Silymarin inhibits the progression of fibrosis in the early stages of liver injury in CCl4-treated rats. J. Med. Food, 18(3):290-8, 2014.

Cubero, F. \& Nieto, N. Kupffer cells and alcoholic liver disease. Rev. Esp. Enferm. Dig., 98(6):460-72, 2006.

Das, S.; Partha, R.; Auddy, R. \& Mukherjee, A. Silymarin nanoparticle prevents paracetamol-induced hepatotoxicity. Int. J. Nanomedicine, 6:1291-301, 2011.

Elhelaly, A.; AlBasher, G.; Alfarraj, S.; Almeer, R.; Bahbah, E.; Fouda, M.; Bunga u, S.; Aleya, L. \& Abdel-Daim, M. Protective effects of hesperidin and diosmin against acrylamide-induced liver, kidney, and brain oxidative damage in rats. Environ. Sci. Pollut. Res. Int., 26(34):35151-62, 2019.

Ferenbach, D. \& Hughes, J. Macrophages and dendritic cells: what is the difference? Kidney Int., 74(1):5-7, 2008.

Ghorbel, I.; Elwej, A.; Jamoussi, K.; Boudawara, T.; Kamoun, N. \& Zeghal, N. Potential protective effects of extra virgin olive oil on the hepatotoxicity induced by co-exposure of adult rats to acrylamide and aluminum. Food Funct., 6(4):1126-35, 2015.

Gren', A. Effects of vitamin E, C and D supplementation on inflammation and oxidative stress in streptozotocin-induced diabetic mice. Int. J. Vitam. Nutr. Res., 83(3):168-75, 2013.

Harrison, S.; Torgerson, S.; Hayashi, P.; Ward, J. \& Schenker, S. Vitamin $\mathrm{E}$ and Vitamin $\mathrm{C}$ treatment improves fibrosis in patients with non-alcoholic steatohepatitis. Am. J. Gastroenterol., 98(11):2485-90, 2003.

Hogervorst, J.; Baars, B.; Schouten, L.; Konings, E.; Goldbohm, R. \& van den Brandt, P. The carcinogenicity of dietary acrylamide intake: A comparative discussion of epidemiological and experimental animal research. Crit. Rev. Toxicol, 40(6):485-512, 2010.

Horio, F.; Kiyama, K.; Kobayashi, M.; Kawai, K. \& Tsuda, T. Ascorbic acid deficiency stimulates hepatic expression of inflammatory chemokine, cytokine-induced neutrophil chemoattractant-1, in scurvy-prone ODS rats. J. Nutr. Sci. Vitaminol., 52(1):28-32, 2006.

Huseyin, S.; Guclu, O.; Yüksel, V.; Erkul, G.; Can, N.; Turan, F. \& Canbaz, $\mathrm{S}$. Avoiding liver injury with papaverine and ascorbic acid due to infrarenal cross-clamping: an experimental study. Braz. J. Cardiovasc. Surg., 32(3):197-201, 2017.

Kara, E.; Coskun, T.; Kaya, Y.; Yumus, O.; Vatansever, S. \& Var, A. Effects of silymarin and pentoxifylline on matrix metalloproteinase1 and -2 expression and apoptosis in experimental hepatic fibrosis. Curr. Ther. Res. Clin. Exp., 69(6):488-502, 2008.

Kim, M.; Yang, S.; Kim, J.; Lee, J.; Kim, Y. \& Lee, J. Silymarin suppresses hepatic stellate cell activation in a dietary rat model of non-alcoholic steatohepatitis: analysis of isolated hepatic stellate cells. Int. J. Mol. Med., 30(3):473-9, 2012.

Kolios, G.; Valatas, V. \& Kouroumalis, E. Role of Kupffer cells in the pathogenesis of liver disease. World J. Gastroenterol., 12(46):7413-20, 2007.

Kurahashi, T.; Lee, J.; Nabeshima, A.; Homma, T.; Kang, E.; Saito, Y. \& Fuji, J. Ascorbic acid prevents acetaminophen-induced hepatotoxicity in mice by ameliorating glutathione recovery and autophagy. Arch. Biochem. Biophys., 604:36-46, 2016.

Lefkowitch, J.; Haythe, J. H. \& Regent, N. Kupffer cell aggregation and perivenular distribution in steatohepatitis. Mod. Pathol., 15(7):699-704, 2002.

Lehning, E.; Balaban, C.; Ross, J. \& Lo Pachin, R. Acrylamide Neuropathy: III. Spatiotemporal characteristics of nerve cell damage in forebrain. Neurotoxicology, 24(1):125-36, 2003.

Li, L.; Sun, H.; Liu, W.; Zhao, H. \& Shao, M. Silymarin protects against acrylamide-induced neurotoxicity via Nrf2 signalling in PC12 cells. Food Chem. Toxicol., 102:93-101, 2017.

Makhlouf, H.; Saksouk, M.; Habib, J. \& Chahine, R. Determination of antioxidant activity of saffron taken from the flower of Crocus sativus grown in Lebanon. Afr. J. Biotechnol., 10(41):8093-100, 2011. 
Manière, I.; Godard, T.; Doerge, D.; Churchwell, M.; Guffroy, M.; Laurentie, M. \& Poul, J. DNA damage and DNA adduct formation in rat tissues following oral administration of acrylamide. Mutat. Res., 580(1):119-29, 2005.

Martinez, E.; Rodriguez, J.; Mondragon, A.; Lorenzo, J. \& Santos, E. Influence of potato crisps processing parameters on acrylamide formation and bioaccessibility. Molecules, 24(21):3827, 2019.

Motamed-Shariaty, V.; Farzad, S.; Nassiri-Asl, M., \& Hosseinzadeh, H. Effects of rutin on acrylamide-induced neurotoxicity. Daru, 22(1):27, 2014.

Mumtaz, S.; Ali, S.; Khan, R.; Andleeb, S.; Ulhaq, M.; Khan, M. A. \& Shakir, H. A. The protective role of ascorbic acid in the hepatotoxicity of cadmium and mercury in rabbits. Environ. Sci. Pollut. Res. Int., 26(14):14087-96, 2019.

Overi, D.; Carpino, G.; Cardinale, V.; Franchitto, A.; Safarikia, S.; Onori, P. \& Gaudio, E. Contribution of resident stem cells to liver and biliary tree regeneration in human diseases. Int. J. Mol. Sci., 19(10):2917, 2018.

Prathibha, P.; Rejitha, S.; Harikrishnan, R.; Das, S.; Abhilash, P. \& Indira, M. Additive effect of alpha-tocopherol and ascorbic acid in combating ethanol-induced hepatic fibrosis. Redox Rep., 18(1):3646, 2013.

Rawi, S.; Marie, M.; Fahmy, S. \& El-Abied, S. Hazardous effects of acrylamide on immature male and female rats. Afr. J. Pharm. Pharmacol., 6(18):1367-86, 2012.

Reuter, S.; Gupta, S.; Chaturvedi, M. \& Aggarwal, B. Oxidative stress, inflammation, and cancer: How are they linked? Free Radic. Biol. Med., 49(11):1603-16, 2010.

Rosen, J. \& Hellenas, K. E. Analysis of acrylamide in cooked foods by liquid chromatography tandem mass spectrometry. Analyst, 127(7):880-2, 2002.

Semla, M.; Goc, Z.; Martiniaková, M.; Omelka, R. \& Formicki, G. Acrylamide: a common food toxin related to physiological functions and health. Physiol. Res., 66(2):205-17, 2017.

Shaker, M.; Zalata, K.; Mehal, W.; Shiha, G. \& Ibrahim, T. Comparison of imatinib, nilotinib and silymarin in the treatment of carbon tetrachloride-induced hepatic oxidative stress, injury and fibrosis. Toxicol. Appl. Pharmacol., 252(2):165-75, 2011.

Shipp, A.; Lawrence, G.; Gentry, R.; McDonald, T.; Bartow, H.; Bounds, J., Macdonald, H.; Clewell, B.; Allen, C.; Landingham, V. Acrylamide: review of toxicity data and dose-response analyses for cancer and non-cancer effects. Crit. Rev. Toxicol., 36(6-7):481608, 2006.

Song, Z.; Deaciuc, I.; Song, M.; Lee, D.; Liu, Y.; Ji, X.; \& McClain, C. Silymarin protects against acute ethanol-induced hepatotoxicity in mice. Alcohol. Clin. Exp. Res., 30(3):407-13, 2006.

Soto, C.; Perez, B.; Favari, L. \& Reyes, J. Prevention of alloxan-induced diabetes mellitus in the rat by silymarin. Comp. Biochem. Physiol. C Pharmacol. Toxicol. Endocrinol., 119(2):125-9,1998.

Stanca, E.; Serviddio, G.; Bellanti, F.; Vendemiale, G.; Siculella, L. \& Giudetti, A. M. Down-regulation of LPCAT expression increases platelet-activating factor level in cirrhotic rat liver: Potential antiinflammatory effect of silybin. Biochim. Biophys. Acta., 1832(12):2019-26, 2013.

Suh, Y. G. \& Jeong, W. I. Hepatic stellate cells and innate immunity in alcoholic liver disease. World J. Gastroenterol., 17(20):2543-51, 2011.

Tamaki, N.; Hatano, E.; Taura, K.; Tada, M.; Kodama, Y.; Nitta, T.; Iwaisako, K.; Seo, S.; Nakajima, A.; Ikai, I. et al. CHOP deficiency attenuates cholestasis-induced liver fibrosis by reduction of hepatocyte injury. Am. J. Physiol. Gastrointest. Liver Physiol., 294(2):G498-G505, 2008.

Tareke, E.; Rydberg, P.; Karlsson, P.; Eriksson, S. \& Törnqvist, M. Analysis of acrylamide, a carcinogen formed in heated foodstuffs. J. Agric. Food Chem., 50(17):4998-5006, 2002.
Veenapani, S.; Bai, M.; Uma, A.; Venkatasubbaiah, K.; Rao, K. \& Thyagaraju, K. Glutathione-s-transferase protein, nucleic acid, chromatin, cell nuclei and structural variation analysis of erythrocyte, bone marrow cell and hepatocytes of rats under the influence of acrylamide. Bioscan, 5(3):477-83, 2010.

Wu, J. \& Zern, M. Hepatic stellate cells: A target for the treatment of liver fibrosis. J. Gastroenterol., 35(9):665-72, 2000.

Wu, Y. F.; Fu, S. L.; Kao, C. H.; Yang, C. W.; Lin, C. H.; Hsu, M. T. \& Tsai, T. F. Chemopreventive effect of silymarin on liver pathology in HBV X protein transgenic mice. Cancer Res., 68(6):2033-42, 2008.

Yousef, M. I. \& El-Demerdash, F. M. Acrylamide-induced oxidative stress and biochemical perturbations in rats. Toxicology, 219(13):133-41, 2006.

Yu, S. J.; Bae, S.; Kang, J. S.; Yoon, J.-H.; Cho, E. J.; Lee, J.-H.; Kim, Y.J.; Lee, W. J.; Kim, C. Y. \& Lee, H. S. Hepatoprotective effect of vitamin $\mathrm{C}$ on lithocholic acid-induced cholestatic liver injury in Gulo(-/-) mice. Euro. J. Pharmacol., 5(762):247-55, 2015.

Yue, Z.; Chen, Y.; Song, Y.; Zhang, J.; Yang, X.; Wang, J.; Li, 1. \& Sun, Z. Effect of acrylamide on glucose homeostasis in female rats and its mechanisms. Food and chemical toxicology. Food Chem. Toxicol., 135:110894, 2020.

\section{Corresponding author: \\ Dr Ahmed Salman}

Faculty of Medicine

The University of Jordan

Queen Rania Street

Amman

JORDAN

Email: Ahmedsalman1971@gmail.com

Received: 11-05-2020

Accepted: 11-07-2020 